\title{
Kinetic control of particle-mediated calcium carbonate crystallization $\dagger$
}

\author{
Baroz Aziz, Denis Gebauer and Niklas Hedin* \\ Received 27th January 2011, Accepted 4th April 2011 \\ DOI: $10.1039 / \mathrm{c} 1 \mathrm{ce} 05142 \mathrm{c}$
}

\begin{abstract}
By changing the temperature, $\mathrm{pH}$, stirring rate, or time for calcium carbonate crystallization, complex shapes of aggregated calcium carbonates formed. Such shapes have earlier been ascribed to specific interactions with specialized additives. Without polymeric additives, aggregates of vaterite transformed more rapidly into calcite aggregates under slow than under fast stirring. With an anionic polyelectrolyte added, vaterite was stabilized. Larger polycrystalline aggregates of vaterite formed under rapid than under slow stirring, indicative of a particle mediated growth of aggregates controlled by convective currents. The size of the underlying nanoparticles was temperature dependent, with grain sizes of $\sim 20$ to $50 \mathrm{~nm}$ at $20^{\circ} \mathrm{C}$ and $\sim 350 \mathrm{~nm}$ at $90^{\circ} \mathrm{C}$. The small differences in free energy between the anhydrous polymorphs of calcium carbonate made both kinetic and equilibrium dependencies important.
\end{abstract}

\section{Introduction}

Calcium carbonates are common biominerals, integrated in shells, and supporting various organisms. ${ }^{1-5}$ They are an important part of the carbon cycle of the Earth, and used in commercial and technical products. ${ }^{6-11}$ Their detailed structure and mechanisms of formation are currently under intense research. ${ }^{12-21}$ They are commonly structured on a wide range of length scales, ${ }^{22}$ which is reflected in that calcite can crystallize around objects and form mesoscopically structured crystals (mesocrystals) in the presence of various additives. ${ }^{23,24}$

The form and shape of calcium carbonate aggregates depend on the solution conditions applied during reactions. Polymeric additives have been shown to be particularly effective in affecting the shape of the calcium carbonate aggregates and their polymorphism. ${ }^{25-27}$ Evidence is mounting that calcium carbonate crystallization is very often particle mediated..$^{28}$ Out-of-equilibrium properties, such as flow patterns, have been shown to affect aggregation and polymorphism of calcium carbonates. For example Pai et al. controlled polymorphism by varying the stirring rate during precipitation of calcium carbonates in the presence of anionic random block copolymers. ${ }^{29}$ Yan et al. showed the importance of stirring rate for controlling $\mathrm{CaCO}_{3}$ polymorphism also without additives. ${ }^{30}$ A classical view of ionic growth of $\mathrm{CaCO}_{3}$ crystals $^{31}$ cannot explain the observed behavior, as convection is a macroscopic phenomenon. In addition, the traditional view of nucleation and growth of calcium carbonates was recently challenged by Gebauer et al. ${ }^{32}$

Department of Materials and Environmental Chemistry, Arrhenius Laboratory, Stockholm University, SE-106 91 Stockholm, Sweden. E-mail: niklas.hedin@mmk.su.se; Fax: +46-8-152187; Tel: +46-8-162417 $\dagger$ Electronic supplementary information (ESI) available: SEM micrographs, kinetic dependencies for relative amounts of $\mathrm{CaCO}_{3}$ polymorphs when using PAMPS, and TGA data. See DOI: $10.1039 / \mathrm{c} 1 \mathrm{ce} 05142 \mathrm{c}$
They showed that equilibrium clusters of calcium carbonates coexisted in solution with the ions, and Pouget et al. imaged such clusters. ${ }^{33}$ Such clusters appear to be related to amorphous calcium carbonates precipitating from aqueous solutions. Structural aspects of such ACC have been studied with and without additives. ${ }^{16,34-36}$ The free energy differences between calcium carbonates are on the same scale as thermal energies, and Navrotsky showed such differences to be similar to contributions from surface energies for crystalline carbonates. ${ }^{35}$ Hence, kinetic effects could select among polymorphs, by differentially affecting Kelvin (or Gibbs-Thomas) contributions for the different polymorphs. ${ }^{29}$ Here, we show that equilibrium and kinetic interactions are effective for crystallization of calcium carbonates. Aggregated $\mathrm{CaCO}_{3}$ with complex forms, similar to such observed by others, ${ }^{37-41}$ were here reproduced by changing the temperature, $\mathrm{pH}$, stirring rate, or time of reaction.

\section{Result and discussion}

\section{Stirring rate dependencies without polymer added}

Vaterite dominated during early stages. At later stages metastable vaterite and aragonite dissolved for the benefit of calcite. That large amounts of vaterite formed before calcite and aragonite is consistent with the Ostwald-Volmer rule. It states that low density polymorphs are kinetically favored to high density ones, even though they typically have higher energy. Vaterite transformed into calcite, more rapidly for slow stirring than for fast, during reactive mixing of $\mathrm{NaHCO}_{3}$ solutions with $\mathrm{CaCl}_{2}$ solutions at $\mathrm{pH} 8.1$. At $150 \mathrm{rpm}$, all vaterite had transformed within $60 \mathrm{~min}$, but at $1000 \mathrm{rpm}$ mainly vaterite remained after $60 \mathrm{~min}$ (Fig. 1). The polymorphs were identified and quantified using powder X-ray diffraction (XRD) data. Scanning Electron Microscopy (SEM) micrographs are presented for aggregates and intergrown particles in the ESI†. 

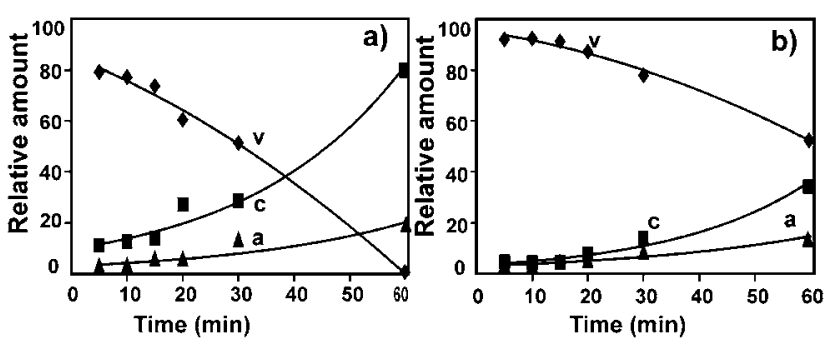

Fig. 1 The time evolution of relative amounts of precipitated $\mathrm{CaCO}_{3}$ polymorphs: vaterite $(\bullet)$, calcite $(\boldsymbol{\square})$ and aragonite $(\boldsymbol{\Delta})$ at (a) a stirring rate of $150 \mathrm{rpm}$ and (b) a stirring rate of $1000 \mathrm{rpm}$. The reaction temperature was $70^{\circ} \mathrm{C}$.

Less vaterite formed initially for slow stirring than for fast. Vaterite transformed to calcite (and aragonite) with a rate $\sim 3$ times faster for slow stirring than for fast, see Fig. 1. Differential dependencies for nucleation on stirring rates can explain the initial different amounts of vaterite. However, they cannot explain the faster rate of transformation of vaterite to calcite for slow stirring as compared with fast. Since the transformation was faster at low than at high stirring rates, neither the dissolution of metastable particles nor a limitation of the flux supplying the growth of calcite was a rate-limiting process. If this would have been the case, an increased mass transport via stirring would have speeded up the transformation, and not retarded it as was observed. This observation and reasoning suggest that the rate limiting process was the growth of aggregated particles. Convective currents can positively increase the aggregation rate by increasing the number of impacts, if not a time period for rearrangement is necessary. To mutually align crystallites with each other demands such time period; this time depends on the size and anisotropy. Here, fast stirring appeared to hinder attachment of primary particles on growing calcite particles either because of their size or shape.

\section{Stirring rate dependencies with an anionic polyelectrolyte added}

With poly(acrylamido-2-methylpropanesulfonic acid (PAMPS)) present during reactions, ACC was detected transiently. No lines were observed in the XRD pattern, and particles in SEM images displayed the spherical form that was expected, see Fig. 2.

Spherical particle shapes are typical for ACC as shown by Shen et al., ${ }^{42}$ and similar sizes of 20-200 nm have been observed for $\mathrm{ACC}{ }^{36} \mathrm{ACC}$ transformed rapidly into vaterite that was

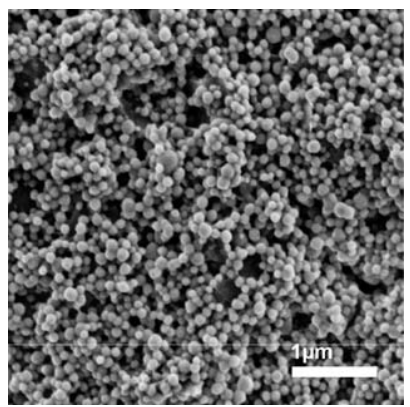

Fig. 2 SEM image of amorphous $\mathrm{CaCO}_{3}$, quenched in liquid $\mathrm{N}_{2}$ just seconds after starting the reaction. stabilized under both rapid and slow stirring. The vaterite/ polymer particles contained $\sim 6 \mathrm{wt} \%$ PAMPS as determined by Thermal Gravimetric Analysis (TGA).

The size of PAMPS stabilized aggregates of vaterite was much smaller for slow than of rapid stirring conditions. Initially, aggregates of $\sim 1$ to $5 \mu \mathrm{m}$ in size formed at $150 \mathrm{rpm}$, and of $\sim 10$ to $15 \mu \mathrm{m}$ in size at $1000 \mathrm{rpm}$ (Fig. $3 \mathrm{a}$ and b).

This dependency on the stirring rate indicates that convective streams controlled the growth of the aggregates, and corroborates our hypothesis of particle-mediated growth and crystallization of calcium carbonate. Semi-spherical aggregates of vaterite formed. The transformation of vaterite into calcite was slow. After $60 \mathrm{~min}$ of stirring, $2 \mathrm{wt} \%$ calcite formed for $1000 \mathrm{rpm}$ and $7 \mathrm{wt} \%$ for $150 \mathrm{rpm}$. As for the additive free reactions, the transformation rate was slower for rapid stirring than for slow. The core of the aggregates started to dissolve or disintegrate. Distinct holes are observed in the aggregates of vaterite in Fig. 3d and e. Larger aggregates of vaterite appeared to have been less stable against disintegration than did the small ones formed under $150 \mathrm{rpm}$ stirring rate. Fig. 3f displays a SEM image for an aged sample that had initially been subjected to mixing at
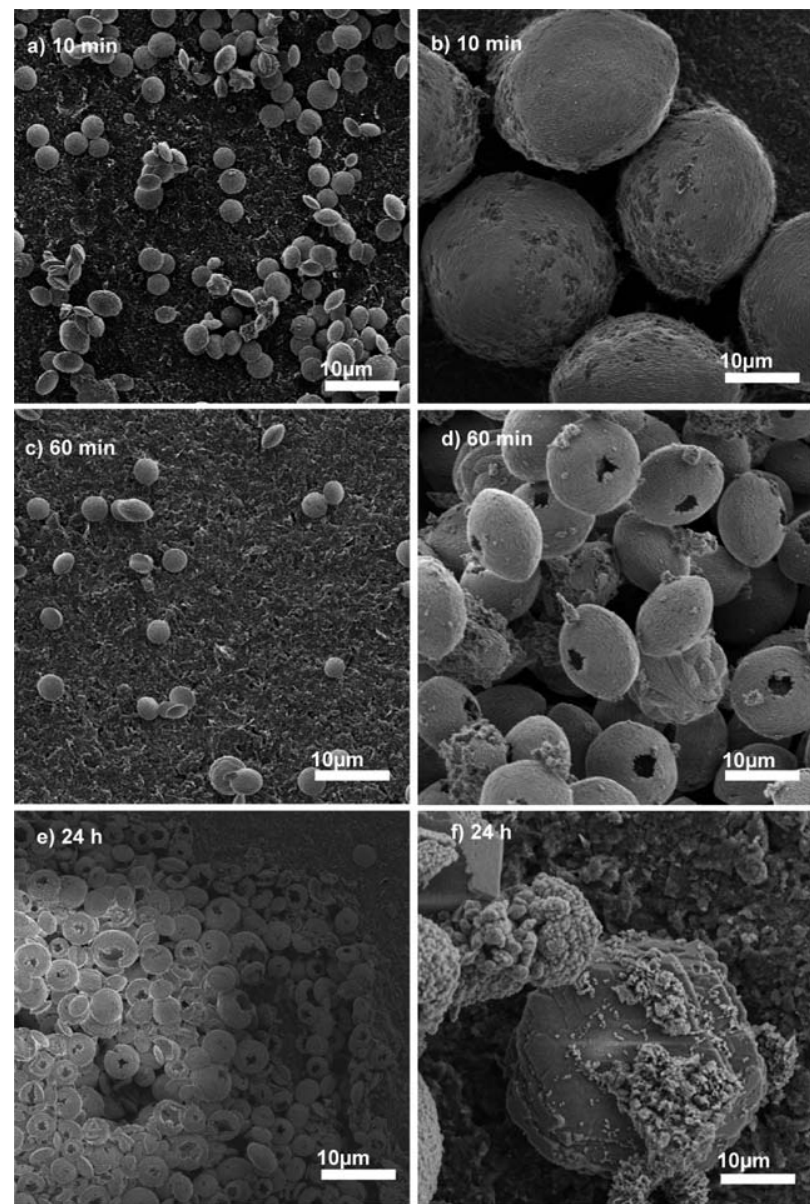

Fig. 3 SEM images of vaterite synthesized at $70{ }^{\circ} \mathrm{C}$ with PAMPS as additive. Left column (stirring at $150 \mathrm{rpm}$ ): (a) after $10 \mathrm{~min}$; (c) after $60 \mathrm{~min}$; and (e) after 24 hours additional aging at stagnant condition. Right column (stirring at $1000 \mathrm{rpm}$ ): (b) after $10 \mathrm{~min}$; (d) after $60 \mathrm{~min}$; and (f) after 24 hours additional aging at stagnant condition. Note the size differences of aggregates in the left and right columns. 
$1000 \mathrm{rpm}$. Almost totally collapsed aggregates of vaterite were observed, besides small amounts of layered aggregates of calcite.

High resolution SEM images of the vaterite aggregates show small particles $(30-100 \mathrm{~nm})$ for both $150 \mathrm{rpm}$ and $1000 \mathrm{rpm}$ of stirring, see Fig. 4. A similar size was observed for ACC particles in Fig. 2. The coinciding length scales indicate that vaterite aggregates were formed by aggregation of nanoparticles (ACC or vaterite). The stabilization of the vaterite nanoparticles of the polymer was kinetic.

\section{Dependencies on temperature, $\mathrm{pH}$ and concentration of PAMPS}

Effects of temperature. The SEM image in Fig. 5a displays spheroidal particles, which are hollow as can be seen from broken shells and other features in the image. At $25{ }^{\circ} \mathrm{C}$, XRD data revealed a mixture of calcite and vaterite particles. The hollow particles and the roundish particles were aggregates of vaterite, facetted particles of calcite were observed. The SEM image in Fig. 5b shows a large portion of spherical Saturn-like aggregates. At $40{ }^{\circ} \mathrm{C}, \mathrm{XRD}$ data revealed a mixture of calcite and vaterite. Similar Saturn-like aggregates were observed by Yao et al. ${ }^{37}$ They although ascribed the formation of such aggregates to a specific interaction of the polypeptide poly(L-lysine) with $\mathrm{CaCO}_{3}$ nanoparticles. The SEM image in Fig. 5c shows hexagonally shaped particles with a layered morphology formed at $60{ }^{\circ} \mathrm{C}, \mathrm{XRD}$ data revealed that these particles were vaterite. A similar layered morphology was observed by $\mathrm{Yao}$ et al. ${ }^{37}$ and $\mathrm{Xu}$ et $a l .,{ }^{38}$ and they related such a morphology to an intricate mechanism including the stabilization of the $\mathrm{CaCO}_{3}$ nanoparticles with $\mathrm{N}$-trimethylammonium derivative of hydroxyethyl cellulose followed by growth via aggregation of these nanoparticles. Please, note that the polymer we employed, PAMPS, actually has an opposite charge to the ammonium rich cellulose derivative used by these authors. The SEM image in Fig. 5d displays aggregated particles of vaterite with irregular morphologies (Fig. 5d). Similar flower-like morphologies were obtained by Zhao et al., ${ }^{41}$ when using solvothermal conditions at $160{ }^{\circ} \mathrm{C}$. At $90{ }^{\circ} \mathrm{C}$, XRD data revealed that only vaterite was present. Vaterite is relatively more stable at higher temperatures than at lower. ${ }^{43}$

XRD data and the Scherrer equation showed that the grain size in the vateritic aggregates was larger at higher temperature than at lower, see Fig. 6 . They were $\sim 50 \mathrm{~nm}$ at $25^{\circ} \mathrm{C}$ and $40{ }^{\circ} \mathrm{C}$, $\sim 200 \mathrm{~nm}$ at $60{ }^{\circ} \mathrm{C}$, and $\sim 350 \mathrm{~nm}$ at $90{ }^{\circ} \mathrm{C}$.
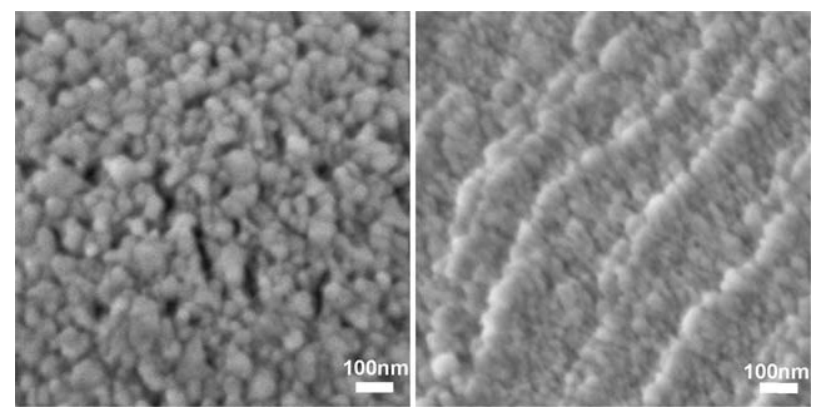

Fig. 4 High resolution SEM of the surface of spheroidal aggregates of vaterites collected after 10 minutes of reaction with PAMPS at (left) a low stirring rate of $150 \mathrm{rpm}$ and (right) a high stirring rate of $1000 \mathrm{rpm}$.
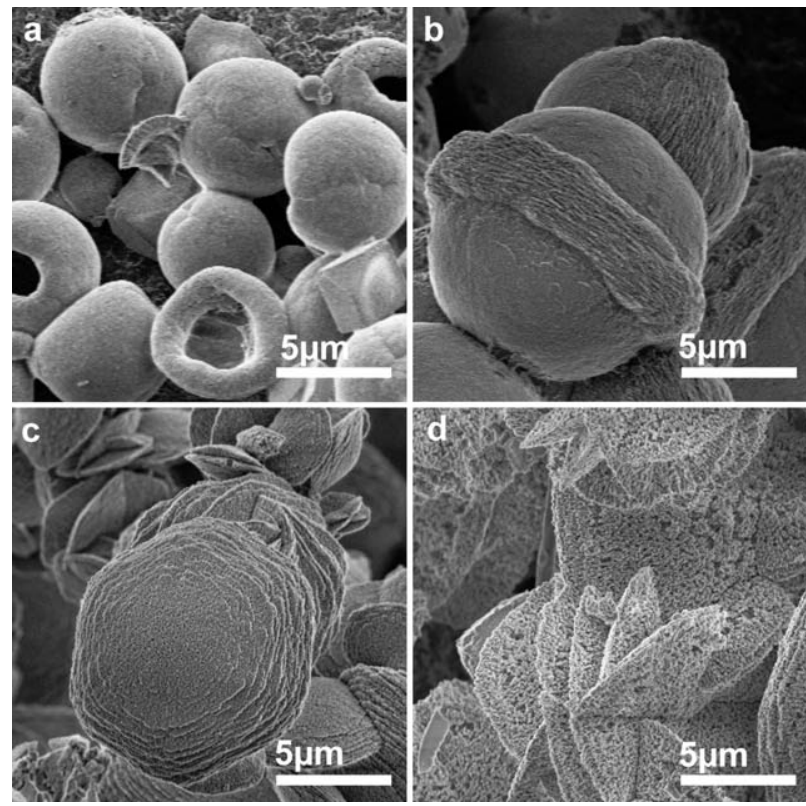

Fig. 5 SEM images of aggregates of $\mathrm{CaCO}_{3}$ synthesized under rapid stirring at $1000 \mathrm{rpm}$ in the presence of PAMPS at different temperatures (a) $25^{\circ} \mathrm{C}$, (b) $40{ }^{\circ} \mathrm{C}$, (c) $60{ }^{\circ} \mathrm{C}$ and (d) $90{ }^{\circ} \mathrm{C}$. The samples were collected after one hour of reaction.

After aging the aggregated particles formed at $25^{\circ} \mathrm{C}$ and $60^{\circ} \mathrm{C}$ in their mother solutions at stagnant conditions thermodynamically stable calcite formed. The SEM images in Fig. 7 show that the morphology of calcite aggregates was different at $25^{\circ} \mathrm{C}$ and $60{ }^{\circ} \mathrm{C}$. The truncated and textured aggregates of calcite in Fig. $7 \mathrm{a}$ are $\sim 10 \mu \mathrm{m}$ along one side. The internal structure of the truncated aggregate appeared to be layered. Wang et al. observed similar morphologies for calcite crystals. ${ }^{40}$ They rationalized such layering by specific interaction of polystyrene sulfonate with calcium carbonate nanoparticles and proposed a particle-mediated growth mechanism. Song et al. presented in a seminal study that calcium carbonate crystallization in certain ways shows aspects of liquid state behavior, and calcitic nanoparticles were captured on P-surfaces. ${ }^{39}$ Possibly, the curved features of the particle in Fig. 7a could relate to an element of liquid-liquid surface energy minimization. The curved features in Fig. 7a are

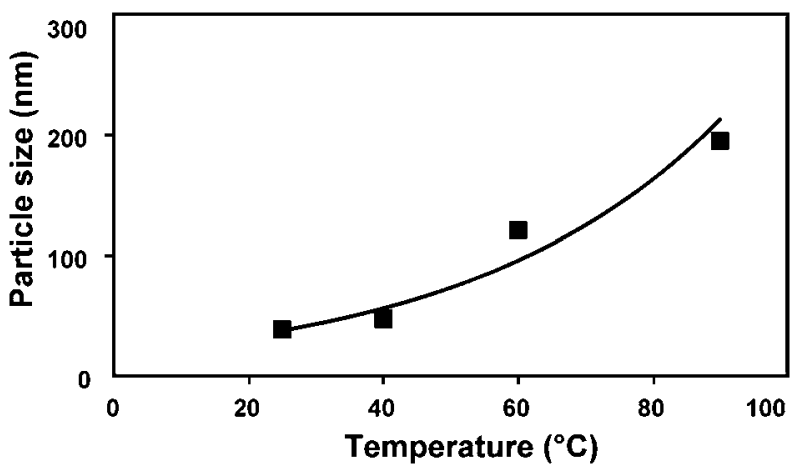

Fig. 6 The average grain/nano-particle size of the particles constituting the aggregates of vaterite versus the reaction temperature. Sizes were calculated from XRD data using the Scherrer equation. 

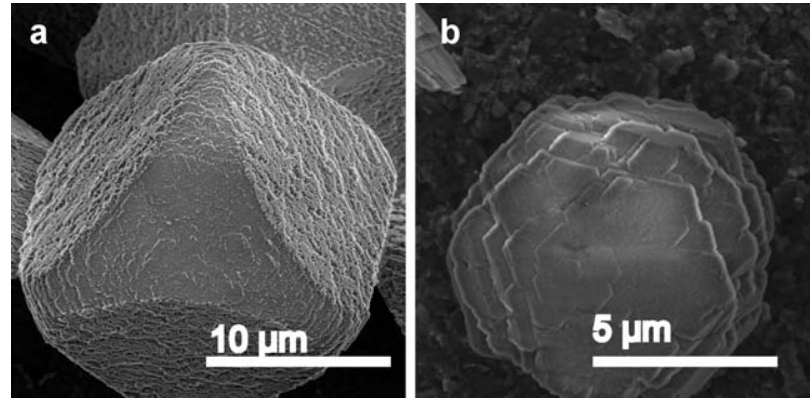

Fig. 7 SEM images of aggregated calcite particles synthesized and aged for 24 hours at (a) $25^{\circ} \mathrm{C}$ and (b) $60{ }^{\circ} \mathrm{C}$. The solutions were subjected to rapid stirring (1000 rpm) for one hour and PAMPS was used as additive.

visible in the curved triangular projection. For the calcite aggregates synthesized at $60{ }^{\circ} \mathrm{C}$, a layered semi-hexagonal morphology was observed, see Fig. 7b. These aggregates appeared to form by recrystallization of the hexagonal and layered aggregates of vaterite similar to those displayed in Fig. 5c.

Effect of pH. The SEM pictures in Fig. 8 show mainly oblatic $(\mathrm{pH}=7.0)$ or Saturn-like $(\mathrm{pH}=7.5)$ aggregates of vaterite, besides a minority phase of calcite. Hollow spheres of vaterite were formed at a pH of 8.1 (Fig. 5a). Changes in the $\mathrm{pH}$ or temperature allowed to change the morphologies of the aggregated vaterite in much the same way. We speculate that tuning either $\mathrm{pH}$ or temperature leads to the generation of similar offequilibrium states that affected aggregation. Certainly, the data strongly indicate that very specific interaction patterns between the polymer and calcium carbonates were not essential for synthesizing particles with complicated morphologies.

Effect of the concentration of PAMPS. The SEM images in Fig. 9 show that aggregates of vaterite nanoparticles and layered rhombohedral calcite crystals formed at low concentration of PAMPS $\left(0.25 \mathrm{wt}^{\%} \%\right)$, and that mainly spheroidal aggregates of vaterite formed $(0.5 \mathrm{wt} \%)$. Collapsed spherical aggregates of vaterite formed at $1.0 \mathrm{wt} \%$ of PAMPS, see Fig. 5a. The amount of calcite is decreased by increasing the concentration of PAMPS, indicating that a critical concentration of PAMPS is
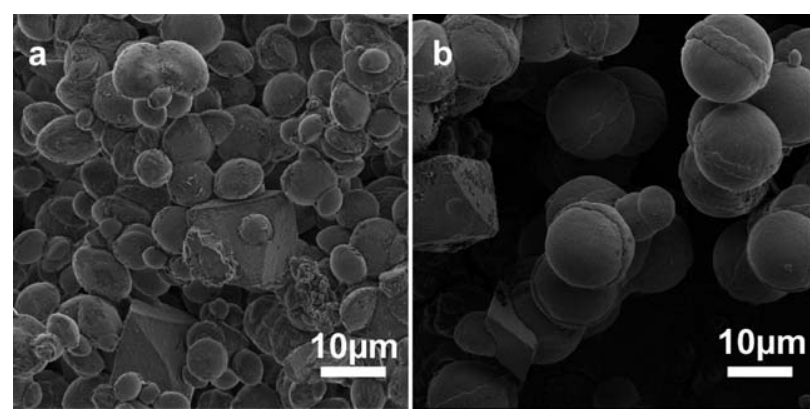

Fig. 8 SEM images of aggregates of $\mathrm{CaCO}_{3}$ synthesized using high stirring at $1000 \mathrm{rpm}$ and with PAMPS as additive. The particles were synthesized at (a) $\mathrm{pH} 7.0$ and (b) $\mathrm{pH} 7.5$, at $25^{\circ} \mathrm{C}$ and one hour of rapid mixing (1000 rpm).
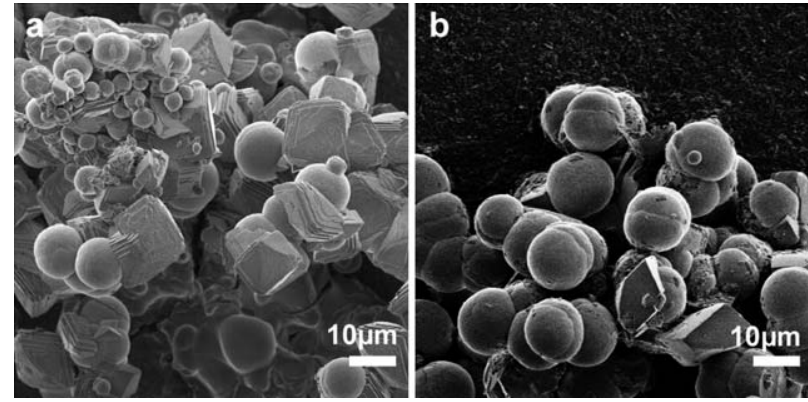

Fig. 9 SEM images of $\mathrm{CaCO}_{3}$ synthesized using high stirring at $1000 \mathrm{rpm}$ and with PAMPS as additive at $25{ }^{\circ} \mathrm{C}$. The particles were synthesized at PAMPS concentrations of (a) $0.25 \mathrm{wt} \%$ and (b) $0.5 \mathrm{wt} \%$.

needed for a kinetic stabilization of nanoparticles of vaterite, or it could be an effect relating to an increasing viscosity on an increasing concentration of PAMPS.

\section{Materials and methods}

Calcium chloride hexahydrate (Sigma-Aldrich 99\% [7774-34-7]), sodium bicarbonate (Sigma-Aldrich 99.7\% [144-55-8]), tris (hydroxymethyl)aminomethane (Tris; Aldrich [77-86-1]), a high molecular anionic polymer, poly(acrylamido-2-methylpropanesulfonic acid) (PAMPS; Alrdich [27119-07-9], $M_{\mathrm{w}}$ 2000 000), and Millipore ${ }^{\mathrm{TM}}$ water were used. Buffered solution of degassed Millipore water and Tris was used, degassing was performed by bubbling of nitrogen overnight. The $0.2 \mathrm{M}$ Tris buffer was adjusted by concentrated $\mathrm{HCl}$. Solutions of $\mathrm{pH}=8.1$, 7.5 and 7.0 were prepared. The temperature was controlled by a heat bath (A VWR digital heat controller model 1136-1D). $5 \mathrm{~mL} \mathrm{~min}{ }^{-1}$ of a Tris-buffered solution of $\mathrm{NaHCO}_{3}(0.125 \mathrm{M})$ were added dropwise into another Tris-buffered $\mathrm{CaCl}_{2}(0.125 \mathrm{M})$ solution. A Labassco ${ }^{\mathrm{TM}}$ mechanical stirrer was used with a blade with a diameter of about $3 \mathrm{~cm}$. A $250 \mathrm{~mL}$ round bottled flask with three openings was used, and the rotating shaft was introduced through a plastic lid. Different stirring rates were used, 150 and $1000 \mathrm{rpm}$. Opaque mixtures were obtained directly after mixing the two solutions. Small amounts of liquid $(10 \mathrm{~mL})$ were removed from the reaction mixtures, and particles were separated from the slurry by a centrifugation at $6000 \mathrm{rpm}$ for 30 seconds using a Hettich EBA 21 centrifuge. The liquid was decanted, and the particles washed with pure ethanol (VWR, 99.9\%) [64-17-5], after which they were filtered and vacuum dried overnight. The samples were analyzed by powder X-ray diffraction and electron microscopy. For syntheses with polymer added, PAMPS was mixed with Tris-buffered $\mathrm{CaCl}_{2}$ solutions for $60 \mathrm{~min}$ to a total concentration corresponding to $1 \mathrm{wt} \%$, $0.5 \mathrm{wt} \%$, or $0.25 \mathrm{wt} \%$. After which the syntheses and the sample work-up procedures were conducted as described above. In the presence of polymer, one sample was removed very rapidly after mixing $(\sim 3 \mathrm{~s})$, and quenched in liquid $\mathrm{N}_{2}$ and subsequently freeze dried using a Hetosicc CD 52-1 freeze dryer.

\section{TGA}

A Perkin Elmer TAG 7 instrument recorded changes in mass on varying the temperature in still flow of dry air $\left(35 \mathrm{~mL} \mathrm{~min}^{-1}\right)$, at temperatures $50-950^{\circ} \mathrm{C}$, using a platinum cup and a sweep rate 
of $10{ }^{\circ} \mathrm{C} \mathrm{min}^{-1}$. The amounts of organics were determined by change in mass in the temperature interval: $200-500{ }^{\circ} \mathrm{C}$.

\section{XRD}

A X'Pert PANanalytical diffractometer with an $X^{\prime}$ Celerator detector was used. Patterns were recorded between $5^{\circ}$ and $70^{\circ}$

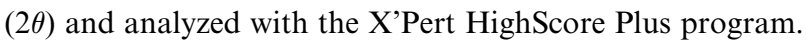

\section{SEM}

For SEM experimentation samples were prepared by sprinkling them on Oxford Aluminium stubs coated by dry and colloidal carbon. A JEOL JSM-7000F microscope was used with an acceleration voltage between $0.8-2.5 \mathrm{kV}$.

\section{Conclusion}

Aggregates of crystalline calcium carbonates formed via particlemediated growth processes with and without addition of a polymeric crystallization additive (PAMPS). During these processes different polymorphs and morphologies developed. The polymer tended to stabilize vaterite aggregates, but did not exert a one-toone specific influence on the crystallization of $\mathrm{CaCO}_{3}$ and morphologies of the aggregated particles. Complex morphologies of aggregated $\mathrm{CaCO}_{3}$ observed by others were here reproduced by simple means, such as changing the temperature, $\mathrm{pH}$, stirring rate, or time of reaction. It appears to be insufficient to ascribe such complex morphologies to very specific interactions without conducting numerous control experiments. Detailed shape and size of aggregates of calcium carbonates related to particle-aggregation mediated processes and not, necessarily, on very specific interaction patterns between PAMPS and nanoparticles of calcium carbonates. The underlying nanoparticles of calcium carbonate appeared to develop under (micro) equilibrium control, with an increased rate of growth at higher temperatures. PAMPS did not provide a specific stabilization of polymorphs or morphologies. On the path to the stabilized aggregated phase of calcium carbonate, a number of local free energy minima were kinetically probed. By combining intense and extensive solution conditions, different minima developed and temporarily stabilized certain morphologies of calcium carbonates. In particular, differences in convective currents affected both the morphology and (indirectly) the polymorphology of calcium carbonate aggregates, with and without PAMPS added. We conclude that the control of the morphology on a micrometre length scale was largely driven by external conditions such as convective currents, but the polymorphology was still controlled by local (micro)equilibrium. No evidence for ion-mediated dissolution/re-crystallization processes was observed. The relevant nanoparticles appeared to be ACC nanoparticles.

\section{Acknowledgements}

Supported by the Institute Excellence Centre CODIRECT. D. G. was supported by postdoctoral grants of the Wenner-Gren Foundations. Knut and Alice Wallenberg Foundations are acknowledged for an equipment grant.

\section{References}

1 A. H. Lowenstam and S. Weiner, On Biomineralization, Oxford University Press, New York, USA, 1989.

2 G. Falini, S. Albeck, S. Weiner and L. Addadi, Science, 1996, 271, 67.

3 J. Aizenberg, J. Hanson, M. Ilan, L. Leiserowitz, T. F. Koetzle, L. Addadi and S. Weiner, FASEB J., 1995, 9, 262.

4 N. Gehrke, N. Nassif, N. Pinna, M. Antonietti, H. S. Gupta and H. Cölfen, Chem. Mater., 2005, 17, 6514.

5 L. Addadi and S. Weiner, Angew. Chem., Int. Ed., 1992, 31, 153.

6 C. M. Chan, J. S. Wu, J. X. Li and Y. K. Cheung, Polymer, 2002, 43, 2981.

7 A. J. Domb, N. Manor and O. Elmalak, Biomaterials, 1996, 17, 411.

8 G. J. Gascho and M. B. Parker, Agron. J., 2001, 93, 1305.

9 A. F. Lemos and J. M. F. Ferreira, Mater. Sci. Eng., 2000, 11, 35.

10 J. Pera, S. Husson and B. Guilhot, Cem. Concr. Compos., 1999, 21, 99.

11 W. Wei, G. Ma, G. Hu, D. Yu, T. Mcleish, Z. Su and Z. Shen, J. Am. Chem. Soc., 2008, 130, 15808.

12 J. Ahmed, Menaka and A. K. Ganguli, CrystEngComm, 2009, 11, 927.

13 L. Addadi, S. Raz and S. Weiner, Adv. Mater., 2003, 15, 959.

14 G. A. Tribello, F. Bruneval, C. Liew and M. Parrinello, J. Phys. Chem. B, 2009, 113, 11680.

15 C. J. Stephens, S. F. Ladden, F. C. Meldrum and H. K. Christenson, Adv. Funct. Mater., 2010, 20, 2108.

16 A. V. Radha, T. Z. Forbes, C. E. Killian, P. U. P. A. Gilbert and A. Navrotsky, Proc. Natl. Acad. Sci. U. S. A., 2010, 107, 16438.

17 Y. Politi, R. A. Metzler, M. Abrecht, B. Gilbert, F. H. Wilt, I. Sagi, L. Addadi, S. Weiner and P. U. P. A. Gilbert, Proc. Natl. Acad. Sci. U. S. A., 2008, 105, 20045.

18 Y. Politi, D. R. Batchelor, P. Zaslansky, B. F. Chmelka, J. C. Weaver, I. Sagi, S. Weiner and L. Addadi, Chem. Mater., 2010, 22, 161.

19 F. M. Michel, J. McDonald, J. Feng, B. L. Phillips, L. Ehm, C. Tarabrella, J. B. Parise and R. J. Reeder, Geochim. Cosmochim. Acta, 2008, 72, A626.

$20 \mathrm{~J}$. Aizenberg, G. Lambert, S. Weiner and L. Addadi, J. Am. Chem. Soc., 2002, 124, 32.

21 L. B. Gower, Chem. Rev., 2008, 108, 4551-4627.

$22 \mathrm{H}$. Cölfen and M. Antonietti, Mesocrystals and Nonclassical Crystallization, John Wiley \& Sons, Chichester, UK, 2008.

23 C. H. Lu, L. M. Qi, H. L. Cong, X. Y. Wang, J. H. Yang, L. L. Yang, D. Y. Zhang, J. M. Ma and W. X. Cao, Chem. Mater., 2005, 17, 5218.

24 F. C. Meldrum and H. Cölfen, Chem. Rev., 2008, 108, 4332.

25 T. Kato, A. Sugawara and N. Hosoda, Adv. Mater., 2002, 14, 869.

26 N. A. J. M. Sommerdijk and G. de With, Chem. Rev., 2008, 108, 4499.

27 H. Cölfen, Curr. Opin. Colloid Interface Sci., 2003, 8, 23.

28 M. Niederberger and H. Cölfen, Phys. Chem. Chem. Phys., 2006, 8, 3271.

29 R. K. Pai, K. Jansson and N. Hedin, Cryst. Growth Des., 2009, 9, 4581.

30 F. Yan, S. Zhang, C. Guo, X. Zhang, G. Chen, F. Yan and G. Yuan, Cryst. Res. Technol., 2009, 44, 725.

31 J. P. Andreassen, J. Cryst. Growth, 2005, 274, 256-264.

32 D. Gebauer, A. Völkel and H. Cölfen, Science, 2008, 322, 1819.

33 E. M. Pouget, P. H. H. Bomans, J. A. C. M. Goos, P. M. Frederik, G. de With and N. A. J. M. Sommerdijk, Science, 2009, 323, 1455.

34 A. Gal, S. Weiner and L. Addadi, J. Am. Chem. Soc., 2010, 132, 13208.

35 A. Navrotsky, Proc. Natl. Acad. Sci. U. S. A., 2004, 101, 12096.

36 D. Gebauer, P. N. Gunawidjaja, J. Y. P. Ko, Z. Bacsik, B. Aziz, L. J. Liu, Y. F. Hu, L. Bergström, C. W. Tai, T.-K. Sham, M. Edén and N. Hedin, Angew. Chem. Int. Ed., 2010, 49, 8889.

37 Y. Yao, W. Dong, S. Zhu, X. Yu and D. Yan, Langmuir, 2009, 25, 13238.

38 A. W. Xu, M. Antonietti, H. Cölfen and Y. P. Fang, Adv. Funct. Mater., 2006, 16, 903.

39 R. Song, H. Cölfen, A. Xu, J. Hartmann and M. Antonietti, ACS Nano, 2009, 3, 1966.

40 T. Wang, M. Antonietti and H. Cölfen, Chem.-Eur. J., 2006, 12, 5722.

41 Z. Zhao, L. Zhang, H. Dai, Y. Du, X. Meng, R. Zhang, Y. Liu and J. Deng, Microporous Mesoporous Mater., 2011, 138, 191.

42 Q. Shen, H. Wei, Y. Zhou, Y. P. Huang, H. R. Yang, D. J. Wang and D. F. Xu, J. Phys. Chem. B, 2006, 110, 2994.

43 A. G. Turnbull, Geochim. Cosmochim. Acta, 1973, 37, 1593-1601. 